Trinity University

Digital Commons @ Trinity

Art and Art History Faculty Research

Art and Art History Department

2017

\title{
The Crisis of Jackson Pollock's Mural as a Painting
}

Michael Schreyach

Trinity University,mschreya@trinity.edu

Follow this and additional works at: https://digitalcommons.trinity.edu/art_faculty

Part of the History of Art, Architecture, and Archaeology Commons

\section{Repository Citation}

Schreyach, M. (2017). The crisis of Jackson Pollock's Mural as a Painting. Getty Research Journal, 9(Suppl. 1), 183-199. doi:10.1086/ 695874

This Article is brought to you for free and open access by the Art and Art History Department at Digital Commons @ Trinity. It has been accepted for inclusion in Art and Art History Faculty Research by an authorized administrator of Digital Commons @ Trinity. For more information, please contact jcostanz@trinity.edu. 


\section{The Crisis of Jackson Pollock's Mural \\ as a Painting}

Michael Schreyach

\section{Immediacy and Representation}

Critics frequently describe Pollock's allover painted fields, especially those he began producing after 1947, as absorbing or engulfing the viewer, occasioning a sensation of being immersed within an all-encompassing visual environment. His paintings are said to establish so powerful a continuity between viewer and painting that the distinction between them collapses, generating a feeling of what the psychologist Anton Ehrenzweig notoriously described as "undifferentiated oceanic envelopment." Pollock's works, he continued, "enveloped the spectator inside the picture plane," producing a "manic experience of mystic oneness." In them, "pictorial space advances and engulfs [the viewer] in a multi-dimensional unity where inside and outside merge." 3 On this account, Pollock's art is immediate, commanding an irresistible connection or mysterious identification.

To express Ehrenzweig's view in other terms, we might say that Pollock's works radically subverted certain conventions - particularly those associated with mimetic easel painting - that traditionally had mediated the relationship between a viewer and a painting and that had established their separateness. While it is true that conventions of illusionism had facilitated the spectator's imaginative access to the fictional world of the work of art, they also served to make conspicuous a distinction between the actual or empirical viewer and the beholder anticipated or projected by the painting. Certainly, conventional techniques of illusionism, spatial composition, narrative arrangement, and the perspectival positioning of the onlooker were the primary means by which easel painters connected the space of the beholder to the space of the painting. But when successful, the sheer veracity of the illusioned scene-not only pictorially delimited but also literally framed as it was-confirmed for the viewer, in a kind of dialectical reversal, the absolute distinction between her own actual standpoint in reality and her imagined place in the depiction. This moment of critical alertness inevitably called to mind a further distinction between the physical properties of the material object and its pictorial content. Acknowledging the conventions as well as the technical strategies by which the artist guided her connection to the illusioned scene, the beholder could not help but be made aware of the difference between the picture as a literally constructed object and the fictional order established by the work of art that held her attention. ${ }^{4}$

Getty Research Journal, no.9, s1 (2017): 183-99 (C) 2017 Michael Schreyach 
Insofar as Ehrenzweig sees Pollock's works as eschewing such conventions in order, first, to obliterate the divide between the viewer and the painting, and second, to intensify the viewer's affective experience of oneness, his position rejects the distinction to which I have just alluded as well as the principle of art's mediated or representational status. Since the union of painting and viewer constitutes an identification of subject and object, we would be authorized to conclude, even, that to Ehrenzweig, whatever the viewer feels simply is the painting's meaning. While that ontological overlap might sound appealing because it seems to transcend dualism, Ehrenzweig effectively conflates meaning with experience. ${ }^{5}$

Ehrenzweig's notion of Pollock's antirepresentational immediacy has significant traction within both scholarly and popular accounts of Pollock's art. The assertion that his paintings expand beyond their frames is a ubiquitous cliché, the provenance of which can be traced to (among others) the artist Allan Kaprow, who famously rejected the idea that Pollock's works were "complete" or bounded. "His art gives one the impression," Kaprow claims,

of going on forever... the confines of the rectangular field were ignored in lieu of an experience of a continuum going in all directions simultaneously, beyond the literal dimensions of any work.... The four sides of the painting are an abrupt leaving-off of the activity which our imaginations continue outward indefinitely, as though refusing to accept the artificiality of an "ending."7

Consequently, Pollock's canvases "ceased to become paintings and became environments" that "sucked in" the audience (the rhetorical parallel with Ehrenzweig's later assessment is striking). Kaprow continues: "[T] he entire painting comes out at the participant (I shall call him that, rather than the observer) right into the room." ${ }^{8}$ It is significant that Kaprow substitutes the traditional designation "observer" with the term "participant." In doing so, he critiques the notion of a detached, ideal point of view from which a spectator passively consumes a work of visual art and posits instead an individual who is actively engaged with the work, as if responsible for collaboratively producing its meaning through his or her experiential participation. ${ }^{9}$ The lesson for younger artists, Kaprow concluded, was that they reject the observational viewpoint and "become preoccupied with and even dazzled by the space and objects of our everyday life, either our bodies, clothes, rooms, or, if need be, the vastness of Forty-Second Street."10 The immersion of the viewer-as-participant into Pollock's paintings, reconceived as literal environments, constitutes their meaning-or so Kaprow suggests. Moreover, the critic seems to understand that moment of active reception to be just like the way we find meaning in our everyday experiences - that is, idiosyncratically, simply by encountering and experiencing things in our physical environment. Given Kaprow's premise of the viewer as being a coproducer of meaning, it becomes likely that he, like Ehrenzweig, must see Pollock's work as an example of overcoming representation and mediation. Here, the "vastness" of Forty-Second Street meets the "oceanic" drift of Pollock's immersive spaces to become the flip side of the same coin. 
In their views, the identity of the work of art, and the artist's meaning that it is intended to express, is superseded by the affective and actual experiences of empirical viewers.

I will soon explain the consequences of the antirepresentational position as staked out by Ehrenzweig and Kaprow, but first, a small caveat is called for. It would be dogmatic simply to insist that "experience" has nothing to do with meaning, since our encounters with works of art begin and end in experience. However, there is more than just a heuristic value in distinguishing between what I have been calling actual experience from pictorial meaning. Arguably, the aspects of our experience having the most to do with our attempts to understand the kinds of abstract paintings Pollock and his contemporaries produced are those that are felt by viewers to exist in a critical relation to the range of pictorial effects, intended by the artist, that we are meant to perceive. To the degree that we acknowledge certain pictorial effects as intentionally produced by the artist, we impose upon ourselves a challenge to maintain a sense of his or her expressive means in contradistinction to what we contingently happen to feel or think within our actual experience. ${ }^{11}$

The distinction is crucial. In what is to my mind the strongest argument to distinguish pictorial meaning from actual or literal experience, Michael Fried in 1967 drew out the consequences of conflating the two. Considering the artist Tony Smith's testimony of his nighttime drive along the unfinished New Jersey Turnpike-in which Smith had declared the reality of the unframed situation to signal the end of art-Fried pointed out that what the sculptor relinquished in favor of his actual experience was the conventional nature of art. In other words, Smith's declaration that "there [was] no way you [could] frame [the situation], you just [had] to experience it" entailed a radical "inclusiveness" that undermined the value of an artist's delimitation of his work. For Fried, the abandonment of the frame extinguished the possibility not simply of interpretation (because you do not need to interpret what you "just experience") but also of meaning as such. "Everything [Smith] observes," Fried remarked, "counts as part of [his] situation and hence is felt to bear in some way that remains undefined on his experience." ${ }^{12}$ Since there is no limit to the range of details Smith, or anyone else, might observe about any situation in which he finds himself, there is no way to discern conceptually what is or is not part of the (now utterly displaced) "work," no way to say what should or should not count as part of the work's meaning. There is thus no basis upon which to advance an interpretation of it (since we do not know what "it" is). ${ }^{13}$ In such a scenario, what is rendered irrelevant is the artist's intention: that is, his whole cognitive, embodied, and psychophysiological bearing that enables him to answer - in the form of rejecting, accepting, or transforming - the historical conventions that serve as the tacit background against which he attempts to express his meaning and communicate it to an audience.

What is at stake in the opposition I have been developing is the concept of art's autonomy. On the one hand, I have suggested that "experience," as the term has often been employed with regard to Pollock (couched as "immediacy," "oneness," the "oceanic," or the "environmental"), is practically aligned with the empirical viewer, with 
contingency, context, and affect. On the other hand, I have proposed that meaning as such is correlated with intention, expression, interpretation, and understanding. Moreover, I have asserted that the delimitation of the work of art by the artist is the condition for any account we might give about its meaning, simply because in order to make a claim about meaning - in order to interpret a work of art-we must say what we think is or is not part of the work, and the only way to do so is to make a case about what we think the artist intended the work, and its effects, to be. ${ }^{14}$ (It bears pointing out that our verdict on what the work is - and on what its intended effects are supposed to be-is the basis on which we judge whether the work succeeds or fails to realize the artist's meaning.) Of course, in a critical landscape dominated by the assertion that readers and viewers not only participate in but also actively produce the meaning of the texts and artworks they encounter, criticism sympathetic to modernist claims about meaning must articulate a definition of autonomy that clarifies its theoretical significance. For the present argument, autonomy refers not in a narrow way to the artwork's putative independence or detachment from the sociopolitical world, nor to its strict confinement to a set of technical or formal problems of the medium (a position often associated, rather reductively, with Clement Greenberg). Instead, I invoke a broader notion of autonomy as the independence of the artist's meaning from the viewer's experience. ${ }^{15}$ This preliminary definition of autonomy requires our taking a critical attitude toward the "oneness" that Pollock's critics (and even he himself) claimed was the end of his art. After reviewing Greenberg's critical assessment of Pollock's achievement of autonomy with regard to the artistic conventions of easel painting within which he worked, I will make a case for how I think Pollock responded formally to the challenge of establishing the pictorial identity (the autonomy) of Mural.

\section{Conventions in Crisis}

In order to explain the dramatic increase in the size of his paintings after 1948, Pollock scholars sometimes cite a remark the artist made the year before, in an application for a Guggenheim Fellowship, where he declared the easel picture to be a "dying form."16 While Pollock admitted that he did not yet find the time right for a "full transition from easel to mural," he aimed nonetheless to create pictures that would "constitute a halfway state," and he pointed to Mural as providing a precedent for the possibilities of this new genre. At 160 square feet, it was the largest painting, by area, that Pollock would ever make. And it is one of only two works that he ever made for a specific architectural setting, in this case the entrance hall of Peggy Guggenheim's town house. ${ }^{17}$ In other words, if Mural is indeed a mural, it is nonetheless anomalous in Pollock's body of work. Despite its title, I am skeptical of the categorical designation, whether it is taken literally (to mean that Pollock's painting is designed only for a specific wall) or metaphorically (to suggest that we should consider the image itself as a wall). It is important, I think, not to underestimate Pollock's idea of Mural as still deeply responsive to the conventions of modernist easel painting that the artist, throughout the 1930s, had struggled to master. As a painting, Mural achieved a certain autonomy from its architectural destination. And understanding 
its meaning hangs on properly acknowledging how it formally establishes its independence both from its context and from the contingent experiences of its viewers.

Pollock's remark in his 1947 Guggenheim application registers Greenberg's strong influence, as does the artist's contemporaneous statement for Possibilities magazine (Winter 1947-48), in which he declared emphatically that his painting "[did] not come from the easel." ${ }^{18}$ Earlier in 1947, Greenberg had written that Pollock "point[ed] a way beyond the easel... to the mural, perhaps." ${ }^{19}$ The critic had been working on a longer analysis of the problem, which was eventually published in April $1948 .^{20}$ In "The Crisis of the Easel Picture," he explained that historically, easel painting had been conditioned by its social function: to hang on a wall and to provide the viewer with an illusionistic scene set within a boxlike cavity. The stability of the genre had allowed artists to develop strong principles of internal unity that isolated their pictures, and their pictures' dramatic effects, from the contexts (usually domestic interiors) within which they were viewed. In fact, that boxlike space had been key to establishing both the easel form's independence from its architectural setting and its difference from the merely decorative. The meaning and validity of the artist's expression, Greenberg seems to have thought, rested on establishing these dual distinctions. At the same time, and since the viewer himself was part of the easel painting's actual setting, the autonomy Greenberg ascribed to the easel picture had to derive from a structure of beholding that managed to seal the representation against a viewer's empirical standpoint. What mattered was not where the viewer actually stood, but the point of view that the artist constructed, the vantage point projected by the painting. (In traditional one-point perspective, this is determined by the vanishing point's relative distance from and angle to the picture plane, which corresponds to the notional distance and angle from which the viewer imagines surveying the scene.) Thus the "crisis," in Greenberg's analysis, manifestly concerned the issue of the easel form's constructed point of view.

Modern artists, Greenberg observed, had undermined the conventions of illusionistic space and the traditional laws of composition that had guaranteed the self-sufficiency of the easel picture. From Manet through the cubists, modernists had contracted the boxlike cavity, radically narrowing the illusionistic corridor that notionally occupies the far side of the picture plane. At the same time, certain "all-over" techniques (such as the consistent weave of brushstrokes used by the impressionists, or the dispersed, faceted planes favored by cubists) tended to "reduce the picture to an undifferentiated surface." ${ }^{21}$ Those effects brought such paintings to the brink of decoration, as if they were "wallpaper patterns capable of being extended indefinitely." 22 And the problem was getting worse. Recent allover paintings by Pollock and his peers threatened to dissolve into a "hallucinated uniformity." 23 The "dissolution of the picture into sheer texture," Greenberg wrote in his 1961 revision of the essay, had "infect[ed] the whole notion of the genre [of easel painting] with a fatal ambiguity." 24

That pronouncement of a crisis in painting's traditional conventions was fueled by a dire sociological observation. "The Crisis of the Easel Picture" happened to be the 
last in a series of three important articles from late 1947 and early 1948 in which the critic addressed the diminishing capacity of modern art to address critically the social and cultural situation from which it emerged. ${ }^{25}$ In the first essay of the trio, "The Present Prospects of American Painting and Culture" (October 1947), Greenberg wrote that modern industrialization since the mid-nineteenth century had resulted in a pervasive "leveling out and rationalization of culture." ${ }^{26}$ Although the condition itself was nothing new, he found its intensity in the United States exceptionally acute in the 1940s, even as a postwar boom in which consumerism was on the rise had begun to replace the economy of scarcity characteristic of wartime America. Instead of being buoyed by the change, Greenberg expressed the near total "flattening and emptying" of American life. ${ }^{27}$ Attending to the ways modern European artists (specifically the impressionists) had responded historically to the acceleration of industrial development and mechanization, and to the social changes those processes entailed, the critic theorized that they had recognized that modern life could only be "dealt with in material terms." 28 So, he suggested, the tightly covered, meshed surfaces of impressionism registered "naked sensations" that were independent of any metaphysical significance, yielding images that were analogous to modernity's positivist mentality. ${ }^{29}$ In a kind of homeopathic gesture, late nineteenthcentury French artists, experiencing the effects of modernization, openly acknowledged and then absorbed society's materialist premises, as if to inoculate their art against its disease. Impressionist techniques thereby protected the easel genre from modern empiricism, pragmatism, and instrumentalism — a process that enabled it to represent modernity all the more comprehensively. ${ }^{30}$

Greenberg pointed out that contemporary artists, by contrast, were turning a blind eye to modern positivism, avoiding its reality by indulging in escapist fantasies. American painters had "difficulty in acknowledging and stating the dull horror" of their existence. ${ }^{31}$ Consequently, they were driven to ever more evasive and extreme affective positions: "We [in the United States]," he explains, "confronted more immediately by the paraphernalia of industrialism, see the situation as too overwhelming to come to terms with, and look for an escape in transcendent exceptions and aberrated states." ${ }^{32}$ That quasi-romantic avoidance, he thought, caused artists to fall back on clichés, and prevented the realization of an art that could "answer contemporary life, [and] found our sensibilities." ${ }^{33}$ To Greenberg's eyes in 1948, finding art that confronted the problems of the historical period without attempting to escape them in "spasmodic" feeling seemed a nearly impossible task. ${ }^{34}$ The second essay of the trio, "The Situation at the Moment" (January 1948), intensifies his rhetoric. "Mercilessness and pessimism," the reader is told, are required to "confront the situation as it is." ${ }^{35} \mathrm{He}$ continued: "Isolation, or rather the alienation that is its cause, is the truth-isolation, alienation, naked and revealed unto itself, is the condition under which the true reality of our age is experienced. And the experience of this true reality is indispensible to any ambitious art." 36

At this point, Greenberg's argument takes an unexpected turn. He says that representing the condition — creating art out of it—requires the abandonment of easel 
painting in favor of something like the mural (but, as we will see, not exactly like it). Why? He proposes a dialectical answer. At the very moment the abstract artist finds himself suffering his isolation in private - and at the same time as the difficulties and demands of his art become ever less appreciated by the public - he is motivated to enlarge his painting in order to give his assessment of the historical situation public form. Greenberg never explains exactly what fuels that motivation, admitting only that it is "as persistent [an urge] as it is largely unconscious." ${ }^{37}$ The amplified pictures the critic projects as resulting "would spread over [the wall] and acknowledge its physical reality" without "becoming identified with the wall like a mural." ${ }^{38}$ Ironically, the painter's anticipation of an architectural destination - and thus of a social location - for the reception of his art contrasts strikingly with the private, albeit existentially isolated, conditions of its creation. Perhaps we can understand that contradiction as what makes the genre contemplated by Greenberg (and Pollock) as one that is "halfway" between the easel and mural.

That irresolvable contradiction between painting and its architectural destination-between the alienated conditions under which individuals produced paintings as expressions of their private selves and the distant public toward which they almost hopelessly reached-specifically defines the crisis Greenberg describes in the last of his three essays, “The Crisis of the Easel Picture," with which I began this discussion. If the conventions of easel painting could no longer sufficiently guarantee the artist's expression and the autonomy of the work of art, new means of securing its independence were necessary. Greenberg discovered them in Pollock. The strength of his paintings, the critic argued, was in the "emphatic surfaces of his pictures, which it is his concern to intensify in all that thick, fuliginous flatness." ${ }^{39}$ Pollock's work, despite its admittedly gothic paranoia and resentment (qualities Greenberg dismissed), was "an attempt to cope with urban life" by concerning itself with "immediate sensations." " It was "positivist [and] concrete." ${ }^{41}$ The allover paintings by Pollock and others were "knit together of a multiplicity of identical or similar elements, repeat[ed] ... without strong variation from one end of the canvas to the other and [had] dispense[d], apparently, with beginning, middle and ending." ${ }^{42}$ Greenberg did not know quite what to make of the phenomenon of so thoroughly atomized picture surfaces. On one side, he seems to have welcomed the destruction of easel painting at the hands of advanced artists, because it necessitated the creation or establishment of new norms and conventions that could serve "as the vehicle of ambitious art." 43 On the other side, he worried that the seemingly undifferentiated picture surfaces of allover paintings - what he described as their hallucinated uniformity-would compromise the work of art's ability to achieve a self-sufficiency and independence analogous to the older form. ${ }^{44}$

\section{Autonomy and Pictorial Content}

Greenberg's analysis prompts us to reconsider a commonly held but narrow view of autonomy. Later commentators have unfairly accused the critic of upholding the clearly untenable view that art is separate from life, detached from the world, 
removed from or independent of its historical context. Against this reductive cliché, autonomy - on Greenberg's account_-is attained only within and in relation to a set of historical conventions. For him, autonomy is dialectical, its status determined—or better, instituted - by an artist who acknowledges the conventions of his medium as limiting factors that are the very condition of pictorial expression..$^{45}$ And the critic's remarks furthermore direct us to the problem of achieving autonomy during a historical period in which traditional — and even modernist — conditions of painting's self-sufficiency were under extreme pressure. Insofar as Pollock, in 1947, voiced his desire to move beyond easel painting, we might take his views to have been in concert with those of the critic. For him, too, the act of abandoning the easel form was fraught as much with danger as with possibility.

That ambivalence echoes, perhaps, in the apocryphal stories of Pollock's anxiety before the eight-by-twenty-foot stretch of canvas that would become Mural. If, as it seems likely, he felt the weight of his task, I am tempted to speculate that it was not, or not merely, produced by his apprehension about how or what to paint on such a large scale, nor about finishing it on time, nor about pleasing his rich patroness. It would also have been the result of implicitly facing the problem of securing Mural's independence as a painting against its architectural destination (and against charges of decoration). There is evidence that Pollock worried about establishing the pictorial identity of each painting he produced. Lee Krasner recounted that her husband - who sometimes questioned her about where to crop a canvas, or how a picture should be oriented-once simply asked her: "Is this a painting?"46 If the need to verify his successful creation of a painting indicates a chronic preoccupation with achieving expression within a convention (for how else would he know that he had, indeed, made a painting, instead of just covered a surface with paint?), then understanding the basis of that concern is fundamental to understanding his art.

Following Greenberg, I suggest that Pollock's challenge in Mural was to establish for his large-scale work an autonomy analogous to that traditionally associated with easel painting. ${ }^{47}$ Consider, as just one instance of this effort, a work Pollock produced for his 1943 show at Art of This Century, in which autonomy is made into a kind of theme of the imagery. Stenographic Figure (ca. 1942), also on view a bit earlier for Guggenheim's Spring Salon for Young Artists, announces the theme. Pollock depicts a single reclining nude whose sex is marked by a triangle wedged between splayed legs. But given what Kirk Varnedoe called the "willed confusions" of this painting, it is possible to see the composition, as many scholars have, as containing two figures who gesture to each other across a table. ${ }^{48}$ On the canvas surface floats a plethora of calligraphic symbols, rudimentary signs, numbers, and seemingly errant marks. The area between the figures is not so much defined as a spatial volume as it is simply partitioned by the flat shapes it contains. Pollock's division of the surface into distinct planar sections, that is, creates numerous independent zones, despite the allover scattering of marks that helps establish for the painting a consistent virtual picture plane, like a scrim hovering between a viewer and the 
scene. The effect is of a strangely uneven spacing that segregates the protagonists despite the frantic gesticulations they make to each other within their disjointed world.

Stenographic Figure establishes an analogy between the meaning of those gestures - or better, the possibility that they might mean — and the possible meaning of the painting itself for a viewer. But that meaning is not a matter of deciphering Pollock's coded stenography or of reading his strange script. Rather, it has to do with the painting's theme of separateness as the condition of communication. At least, this is how I interpret Pollock's technical choice to render the space so resolutely partitioned and disjointed — as if to recapitulate formally, and to pictorially express, the condition that keeps the figures apart. Perhaps we are also meant to acknowledge the painting's pictorial identity, just as we must acknowledge the identity of another, as the source of our capacity to join in a communicative act.

\section{Mural and Meaning}

In Stenographic Figure, our grasp of Pollock's allegory of communication depends on our identifying what is happening in the scene: two figures gesture to each other across a divide. That allegory applies not just to the figures depicted in the fictional narrative but also extends to the beholder outside the picture, who faces the painting and tries to interpret it. In Mural, or so I shall argue, the painter-beholder relationship as an allegory of (possible) expression, communication, interpretation, and understanding is motivated and sustained by the painting's abstract pictorial effects (see pl. 1).$^{49}$ Pollock seems to have recognized that the conventions or norms that might guarantee painting's autonomy after the desolation of easel painting could be generated out of the specific spatial and perceptual characteristics he created in his painted fields, not just by his narrative imagery.

Mural renders pictorial dimension so insistently flat over such a large surface area that it compromises imaginative projections into depth. In fact, I am tempted to say that the effect of a flattened but still salient depth creates an impression of what Michael Fried has called in another context "facingness," a quality of instantaneous strikingness that produces a powerful sense of the painting's formal and expressive closure. Such an intensified mode of frontal address, Fried explains, served historically to build into a painting "the separateness, distancedness, and mutual facing that had always characterized the painting-beholder relationship." 50

That effect results in part from the complex lateral flow of pictorial energy in Mural between, but not quite around, the predominant, quasi-vertical black lines and arcs. Although those lines do not exactly enclose figural profiles, it would be willful to deny that their structural role is not in some way analogous to a bodily, or perhaps skeletal, propping up of the picture as a manifestly vertical plane. ${ }^{51} \mathrm{I}$ am, however, interested less in seeing the circular forms along the top edge as representing the "heads" of marching stick figures than I am in describing their role in creating Mural's complex dimensionality. There is a difference between the type of space those loops contain and the 


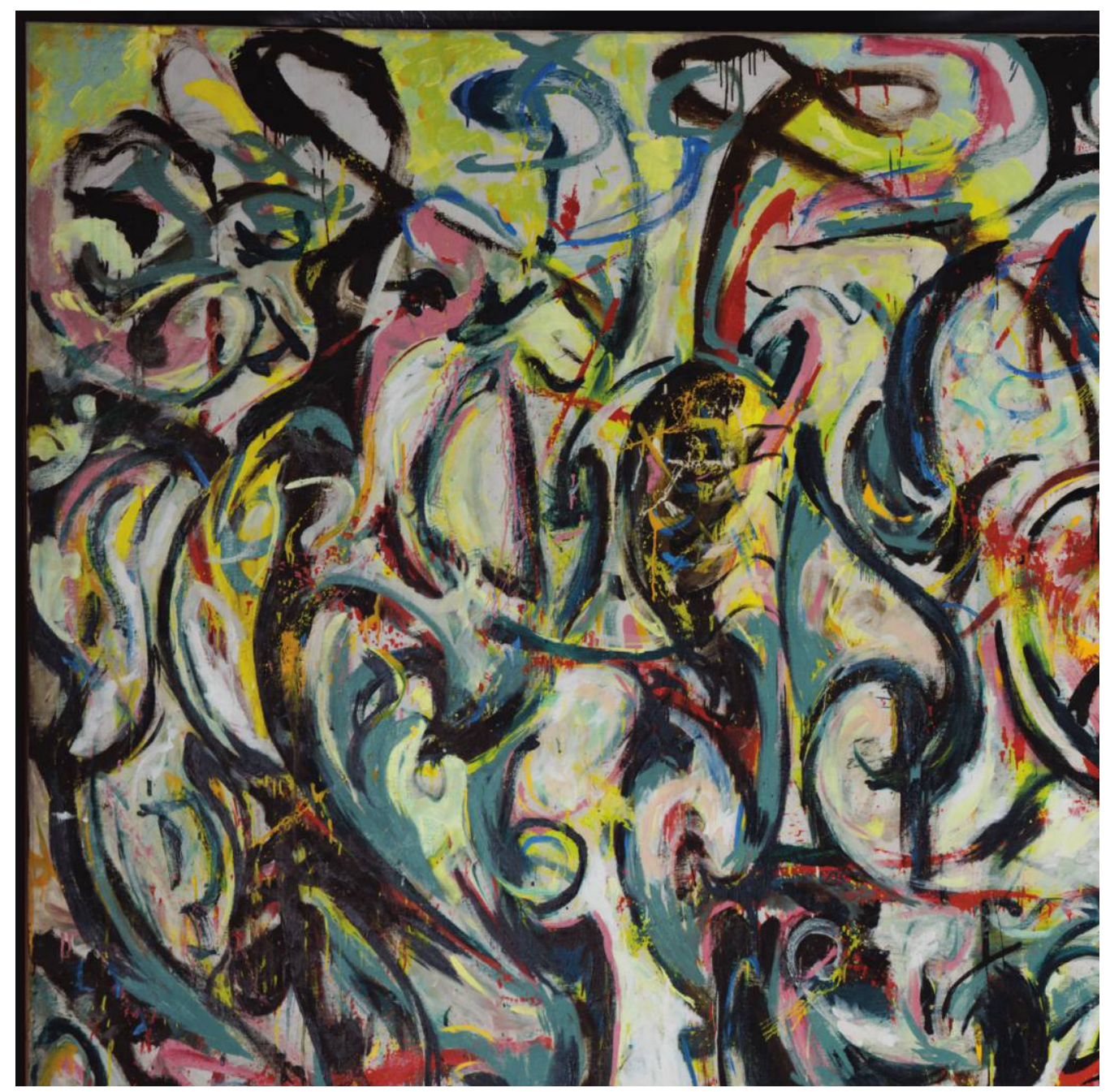

Fig. 1. Detail of Mural (1943) by Jackson Pollock (American, 1912-56), showing canvas reserves along the top framing edge and painted "reserves" nearby.

type-or, I am tempted to say, the modality — of space elsewhere in the painted field. In their catalog essay, the Getty conservators discuss Pollock's use of "light background 'reserves," " the appearance of a primed but otherwise unpainted ground in various places across the surface. ${ }^{52}$ I am drawn to the word "reserve." The term connotes a kind of holding back. Consider the looped canvas reserves as demarcating spaces Pollock meant to dissociate from others he created (fig. 1). The areas lassoed by the coils of black, slate gray, and salmon pink along the top framing edge are pointedly empty: they are flat in the sense that their flatness is felt to be a physical characteristic of the material surface we are, after all, looking at. But there is another kind of "flatness" Mural alludes to. Pollock calls our attention to the literally flat in order to distinguish it from the pictorially flat. In various zones just below the reserves of actual canvas, Pollock offers us that pictorial alternative. Between the more linear elements, he used an off-white trade paint to fill in viscid and 
almost gummy passages; we might think of them as painted "reserves." The surrounding lariats and swirls seem to fasten into them, binding the field and its "ground" to recreate the painting's flatness by preserving the modality of space "behind" the painting's field. ${ }^{53}$ I see Pollock's final layering of the painted reserves as compromising their role as the putative ground against which the linear figures appear in shallow relief. Those light areas suddenly assert themselves, projecting what might otherwise be sensed as a ground plane, or even as indeterminate depth behind the figure, toward the viewer.

Within that field, there is a global distribution of concentrated pictorial energies, a ubiquitous exchange of intensities, that modulates the surface. Three key technical choices heighten the effect. First, the initial paint gestures were not, as many scholars had assumed, the elongated structuring lines, but rather broadly applied patches of red, yellow, and dark teal with blue. ${ }^{54}$ Although that patchwork is obscured by subsequent layers of paint, the logic of starting the work with a partitioned or zone organization might help explain the sense of the field as an aggregate plane, the vitality of which is felt to be infused in every mark and to confront the viewer at every point.

Second, Pollock intended the surface to have differential reflective values. The 1973 conservation effort, which included varnishing the surface, reduced the differences between the matte and glossy paints that Pollock originally used. ${ }^{55}$ Their dissimilar sheen would have made (and, subsequent to the 2012-14 conservation effort, do make) passages of contrasting luster. Mural's variable surface reflectivity creates a fluctuating optical perception, the pulse of which reinforces the plasticity of the image - an image that is seemingly “responsive ... to one's own act of looking” (here again, Fried's description is the most apt). ${ }^{56}$ It is possible that Guggenheim herself noticed and intended to heighten this effect when she installed a special high-luminosity lighting system that further intensified the contrasts. ${ }^{57}$

The effect of a kind of flexible visuality that both connects and counterpoises the viewer and the image is reinforced by a third technical decision. Pollock offers a pointed contrast between wet-into-wet areas and dry passages. The former appear blurrier than those featuring a progressive layering of colors, so that the viewer senses a need to adjust her eyes, and perhaps even change position, to enhance her visual acuity. In other words, Pollock actively manages, and thus places into a point of view, the viewer he anticipated or projected as encountering the work. The viewer's awareness of Pollock's intentional management of the imaginative position she must occupy to "see" the painting is the result of her critical attention to Mural's intended effects. Those effects, in other words, simply are the means by which Pollock fixes the viewer's standpoint and concomitantly establishes the work's autonomy, its separateness.

There is a further technique by which Pollock accomplishes this task, one that returns us to the issue of categorizing the work as essentially an easel painting or as a mural (or something "halfway" between the two). Considering that Mural was commissioned for a specific location, a problem immediately presents itself. Given Pollock's admiration for the mural form, the goal of establishing Mural's identity as a painting 
might seem not only to violate formative aspects of his training (specifically that which he received from Thomas Hart Benton and David Alfaro Siqueiros) but also to contradict his personal and political investment in the form of the public mural, where placement and site have as much to do with its message as its subject matter does. ${ }^{58}$ His self-imposed demand to fix Mural's identity as a painting, separate from the space it was destined for, would then seem not only paradoxical but perhaps hypocritical - a repudiation of his commitment to art's social role..$^{59}$ Nonetheless, it is in relation to Siqueiros that one final observation may be made about how Mural establishes its autonomy.

Visitors to Guggenheim's town house entered through a door at a right angle to Pollock's painting, from which they would have looked down the length of the canvas from right to left (fig. 2). Pollock knew this, and he would have felt the challenge to create an image that would be contained within its frame, despite the lateral acceleration of vision across the surface. While it is certainly not the only constraint that determined the painting's compositional structure, note that the while the right half of the painting contains three or four predominant verticals, the left half of the painting contains a cascade of three or four long arcs, bowing outward from a central zone that seems marked by a prominent blue half-arc anchored to the top framing edge near its midpoint. The full sweep of each arc is interrupted by curlicue vortexes of paint. Their sensual shapes, like swirling eddies, contrast pointedly with the relatively contained circular forms found interspersed among the upright figures. It is possible, of course, that Pollock wanted us to understand that juxtaposition of rigidity and enclosure with openness and voluptuousness as symbolically repeating the unification of male and female energies that was a leitmotif in his work at this moment. Additionally, I see the divided composition as creating, for an angled view, a perceptual effect that solicits the beholder to reposition himself directly in front of the painted field. From a sidelong view, the compositional elements conspire to create the impression of a left-to-right flow of energy - that is, against the direction a viewer, under the conditions of Mural's original setting, initially would have moved. ${ }^{60}$ This sensation of palpable resistance to the lateral directionality of vision is analogous to wading upstream. A resolution to the perceptual tension is achieved when the viewer steps back, as if to sidestep the current, to face the painting from a perpendicular angle.

If I am right about that effect, the dynamic re-situation of the viewer is not unlike that which typically is associated with anamorphosis, the technical construction of a perspectival system in which a depiction appears naturalistically_its elements correctly related in scale and spatial arrangement-from only one particular point of view. The viewer, encountering a perceptually distorted image, attempts to discover and then occupy the perspectival location from which the anamorphic projection resolves. (Perhaps the most famous example of this type of representation in painting is Hans Holbein's The Ambassadors of 1533.) Of course, anamorphosis was a central technique by which Siqueiros stage-directed viewers of his public murals to place themselves at a precise point of perspectival resolution. Indeed, coming to occupy that exact point of 


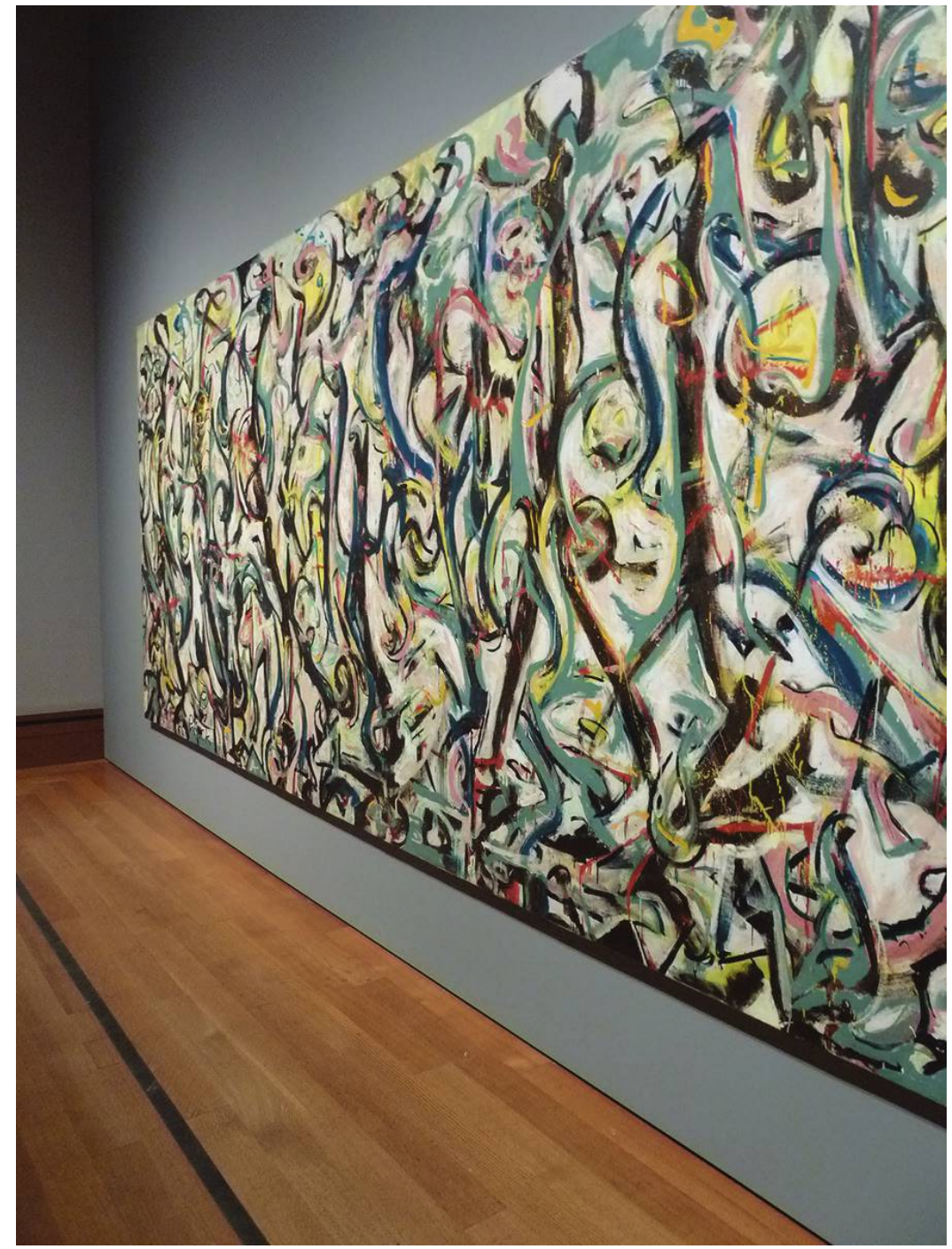

Fig. 2. Installation view of Mural (1943) by Jackson Pollock (American, 1912-56), as installed at the J. Paul Getty Museum, Los Angeles, in 2014, photographed from the approximate angle at which a viewer might have seen it on first entering Peggy Guggenheim's town house.

view allegorized the viewer's coming to occupy a revolutionary standpoint from which a history of ideological and class struggle would become not only visible but forcefully present to her consciousness. ${ }^{61}$

If Mural is any evidence, then Pollock internalized the general idea of anamorphic repositioning. His composition asks the viewer to move outward, away from the picture, and to see it from a distance. Although the imagery will never "resolve" to produce a mimetic image, that repositioning requires the viewer to occupy what is arguably the most conventional position from which to perceive a painting - namely, in front of and facing it. That primordial convention sustains the distinction between the viewer and the work of art that I have been arguing is central to any account of pictorial meaning. At 
least part of the content of Mural has to do with making available, as a pictorial effect, a certain proposition: namely, that its separateness is the condition of Pollock's (possible) expression. Its “autonomy," then, should be understood not in a narrow sense-as the isolation of the work of art from the world - but rather as the independence of its meaning-Pollock's meaning_from our contingent experiences. ${ }^{62}$

Michael Schreyach is an associate professor at Trinity University in San Antonio, Texas.

Notes This essay is the initial version of the author's extended account of Mural, published as chapter 2 ("Anamorphosis") in Pollock's Modernism (New Haven, CT, and London: Yale University Press, 2017), 53-96. Portions of that chapter are reprinted here with the permission of Yale University Press.

1. Anton Ehrenzweig, The Hidden Order of Art: A Study in the Psychology of Artistic Imagination [1967] (Berkeley: University of California Press, 1971), 120.

2. Ehrenzweig, The Hidden Order of Art, 118-19.

3. Ehrenzweig, The Hidden Order of Art, 121.

4. In other words, the picture's interest as a work of art derives not from the degree to which the illusion tricks us - even though we may initially be taken in by it - but rather from our simultaneous awareness that we are, after all, encountering a representation of reality. See Wolfgang Kemp, “The Work of Art and Its Beholder," in The Subjects of Art History: Historical Objects in Contemporary Perspectives, ed. Mark Cheetham (Cambridge: Cambridge University Press, 1998), 180-96.

5. For an excellent critique of these issues in relation to modernist poetry and its criticism, see Gerald Graff, Poetic Statement and Critical Dogma (Chicago: Northwestern University Press, 1970).

6. Allan Kaprow, “The Legacy of Jackson Pollock,” Art News 57, no. 6 (October 1958): 24-26, $55-57$.

7. Kaprow, “The Legacy of Jackson Pollock,” 26, 55; emphasis original.

8. Kaprow, "The Legacy of Jackson Pollock," 56; emphasis original.

9. Compare the analysis in William Kaizen, "Allan Kaprow and the Spread of Painting," Grey Room 13 (Autumn 2003): 80-107. Interestingly, in 1967 Kaprow dramatically reversed this view, writing stridently against the idea that the audience creates the meaning of the work of art by experiential participation. See Kaprow, “Jackson Pollock: An Artists’ Symposium, Part I,” Art News 66, no. 2 (April 1967), 32-33, 59-61.

10. Kaprow, “The Legacy of Jackson Pollock," 56.

11. Todd Cronan distinguishes between intended and actual effects in Against Affective Formalism: Matisse, Bergson, Modernism (Minneapolis: University of Minnesota Press, 2013), 34-38. Cronan writes: "An intended effect is one the artist sought to produce in the beholder...An actual effect, on the other hand, is an effect that occurs in the viewer's mind or body regardless of the artist's intention" to produce it (34).

12. Michael Fried, "Art and Objecthood," Artforum (Summer 1967): 12-23, at 22.

13. For an extended discussion of this point, see Walter Benn Michaels, The Shape of the Signifier: 1967 to the End of History (Princeton, NJ: Princeton University Press, 2004), esp. 1-18.

14. By “intention," I am not referring to intention as narrowly conceived - as a preformed or previsualized mental plan known as if transparently to the agent's introspective consciousness. Nothing about my use of intention prohibits the acknowledgment of unconscious intentions or intentions that fail to be realized. Nor am I suggesting that the problem of understanding an artist's intention-his meaning - can be resolved by finding some statement he made about what the intent was (after all, he could be mistaken in his self-assessment). I am simply making the point that interpreting what an artist means 
requires that we provide an account of what we suppose the agent's intent to be, and that we support our arguments with appropriate forms of evidence (very little of which, in Pollock's case, is going to take the form of explicit documentation). My basic orientation accords with G. E. M. Anscombe, Intention [1957] (Cambridge, MA: Harvard University Press, 1963).

15. For this definition of autonomy, see Jennifer Ashton, From Modernism to Postmodernism: American Poetry and Theory in the Twentieth Century (Cambridge: Cambridge University Press, 2005); and Lisa Siraganian, Modernism's Other Work: The Art Object's Political Life (Oxford: Oxford University Press, 2012).

16. Jackson Pollock, “Application for Guggenheim Fellowship” [September or October 1947], in Jackson Pollock: Interviews, Articles, and Reviews, ed. Pepe Karmel (New York: Museum of Modern Art, 1999), 17.

17. The other was Untitled (Mural) (1950), commissioned by Bertram Geller for his house in Lawrence, Long Island (48 sq. ft.). I am excluding from consideration both Peter Blake's 1949 plans and model for a museum within which to display paintings Pollock had already made, as well as E. A. Carmean's suggestion that Pollock's black-and-white paintings of 1951-52 were made for an unrealized church project by Tony Smith, a thesis more than disproved by Rosalind Krauss. See Peter Blake, "Unframed Space: A Museum for Jackson Pollack's [sic] Paintings," Interiors and Industrial Design 109, no. 6 (January 1950): 90-91; E. A. Carmean Jr. “The Church Project: Pollock's Passion Themes,” Art in America 70, no. 6 (Summer 1982): 110-22; and Rosalind Krauss, “Contra Carmean: The Abstract Pollock,” Art in America 70, no. 6 (Summer 1982): 123-31. See also Megan Luke, this issue, pp. 159-67.

18. Pollock, "My Painting” [1947-48], in Karmel, Jackson Pollock: Interviews, Articles, and Reviews, $17-18$, at 17 .

19. Greenberg, "Review of Exhibitions" [The Nation, 1 February 1947], in Clement Greenberg: The Collected Essays and Criticism, ed. John O'Brian, 4 vols. (Chicago: University of Chicago Press, 1986-93), 2:122-25, at 125. Hereafter cited as CEC followed by volume number.

20. Greenberg, "The Crisis of the Easel Picture" [Partisan Review, April 1948], in CEC, 2:221-25.

21. Greenberg, "The Crisis of the Easel Picture," in CEC, 2:222.

22. Greenberg, "The Crisis of the Easel Picture," in CEC, 2:223.

23. Greenberg, "The Crisis of the Easel Picture," in CEC, 2:224.

24. Greenberg, “The Crisis of the Easel Picture," in idem, Art and Culture: Critical Essays (Boston: Beacon Press, 1961), 154-57, at 157 and 155. In the 1961 revision, Greenberg chose to include the modifier "fatal," which does not appear in the original 1948 publication. Perhaps he wanted to stress, for a generation of readers who may have forgotten it, the depth of that historical crisis.

25. The other two were Clement Greenberg, "The Present Prospects of American Painting and Sculpture" [Horizon, October 1947], in CEC, 2:160-70; and “The Situation at the Moment" [Partisan Review, January 1948], in CEC, 2:192-96.

26. Greenberg, “The Present Prospects of American Painting and Sculpture," in CEC, 2:161.

27. Greenberg, "The Present Prospects of American Painting and Sculpture," in CEC, 2:163.

28. Greenberg, “The Present Prospects of American Painting and Sculpture," in CEC, 2:164.

29. Greenberg, “The Present Prospects of American Painting and Sculpture," in CEC, 2:164. To Greenberg, cubism represented a kind of apogee of this tendency in its resolute focus on medium specificity, and to the three essays I've grouped might be added “The Decline of Cubism” [Partisan Review, March 1948], in CEC 2:211-16.

30. On the relevance of these points for a general theory of modernism, see Richard Shiff, “Homeopathic Criticism," Common Knowledge 7 (Winter 1998): 4-13.

31. Greenberg, "The Present Prospects of American Painting and Sculpture," in CEC, 2:163.

32. Greenberg, “The Present Prospects of American Painting and Sculpture," in CEC, 2:164. 
33. Greenberg, “The Present Prospects of American Painting and Sculpture," in CEC, 2:168.

34. Greenberg, “The Present Prospects of American Painting and Sculpture," in CEC, 2:167.

35. Greenberg, “The Situation at the Moment," in CEC, 2:192.

36. Greenberg, "The Situation at the Moment," in CEC, 2:193.

37. Greenberg, “The Situation at the Moment," in CEC, 2:194.

38. Greenberg, “The Situation at the Moment," in CEC, 2:195.

39. Greenberg, “The Present Prospects of American Painting and Sculpture," in CEC, 2:166.

40. Greenberg, “The Present Prospects of American Painting and Sculpture," in CEC, 2:166.

41. Greenberg, “The Present Prospects of American Painting and Sculpture,” in CEC, 2:166.

42. Greenberg, "The Crisis of the Easel Picture," in CEC, 2:222. When he penned these words in early 1948, Greenberg could have had Mural on his mind, as the work had been exhibited twice in 1947: at Art of This Century (14 January-1 February), and again at MoMA's exhibition Large-Scale Modern Paintings (April-May).

43. Greenberg, "The Crisis of the Easel Picture," in CEC, 2:225.

44. Greenberg, "The Crisis of the Easel Picture," in CEC, 2:222.

45. This issue is, of course, more complex than I may discuss under present circumstances. The key account of Greenberg's “essentialism” is Michael Fried, “An Introduction to My Art Criticism," in idem, Art and Objecthood: Essays and Reviews (Chicago: University of Chicago Press, 1998), esp. 37-40.

46. B. H. Friedman, "An Interview with Lee Krasner Pollock” [1969], in Karmel, Jackson Pollock: Interviews, Articles, and Reviews, 35-38, at 37.

47. Greenberg's assessment of Pollock's relation to the easel and the mural is inconsistent and even contradictory. In 1946, the critic found Pollock to be the "most original contemporary easel-painter under forty" ("Review of Exhibitions" [The Nation, 13 April 1946], in CEC, 2:75), but by 1947 he seemed to think (with some reservations) that Pollock "points a way beyond the easel" ("Review of Exhibitions" [The Nation, 1 February 1947], in CEC, 2:125). In early 1948, Greenberg claimed that Pollock "has driven the easel picture ... away from itself" ("Review of Exhibitions" [The Nation, 24 January 1948], in CEC, 2:201), but in 1949 vacillated again, declaring that Number 1A, 1948 - recently shown at Betty Parsons, and besides Mural one of the largest paintings Pollock had yet produced- "presents an almost square surface that belongs very much to easel painting" ("Review of Exhibitions" [The Nation, 19 February 1949], in CEC, 2:286).

48. For a summary of scholarly positions regarding the number of figures, see Sue Taylor, "The Artist and the Analyst: Jackson Pollock's Stenographic Figure," American Art 17, no. 3 (Autumn 2003): 52-71.

49. Stephen Foster makes a related point in “Turning Points in Pollock's Early Imagery,” University of Iowa Museum of Art Bulletin 1, no. 1 (Spring 1976): 25-37.

50. Michael Fried, Manet's Modernism; or, The Face of Painting in the 1860s (Chicago: University of Chicago Press, 1996), 265.

51. It has become common for scholars to identify these poles with Thomas Hart Benton's compositional strategies as presented in his series of articles, “The Mechanics of Form Organization” (published monthly in five parts in The Arts between November 1926 and March 1927). The Getty conservation team calls them the "anthropomorphic calligraphic gestures of the Bentonian architecture" in Yvonne Szafran et al., “Jackson Pollock's Mural: Myth and Substance,” in Szafran et al., Jackson Pollock's Mural: The Transitional Moment (Los Angeles: J. Paul Getty Museum, 2014), 54. But I think nothing could be further from the pictorial dimensionality that Pollock achieves in Mural than Bentonian space, which aims to convey a sense of three-dimensional rotation or volumetric fullness around compositional anchors. The Bentonian model drives to secure the mural picture ever more permanently to the architecture by almost paradoxical means: by holing out the wall with the illusion of a swelling, quasi-naturalistic, and nearly animate environment, and thereby powerfully locking the picture's narrative into the actual space within which it is encountered - with the end goal being, as Erika Doss has argued, to overcome the separateness 
of the viewer from the depicted world and to heighten the "felt experience and affective conditions" of that narrative; see Doss, “Action, Agency, Affect: Thomas Hart Benton's Hoosier History,” Indiana Magazine of History 105 (June 2009): 127-39, at 136. Ellen Landau suspects the connection to Benton, too. She compares the repetition of vertical forms to the successive movements of walking or dancing captured by stroboscopic photographs, which Pollock encountered both through his friendship with Herbert Matter and in the 1943 MoMA exhibition Action Photography. The fluid compositional model provided by stopmotion photography, she highlights, contrasts with the relative stasis of Benton's diagrams; see Landau, “Still Learning from Pollock," in Szafran et al., Jackson Pollock's Mural: The Transitional Moment, 22.

52. Szafran et al., "Jackson Pollock's Mural: Myth and Substance," 36.

53. On "re-created” flatness, see Michael Schreyach, “Re-created Flatness: Hans Hofmann's Concept of the Picture Plane as a Medium of Expression," Journal of Aesthetic Education 49, no. 1 (Spring 2015):44-67.

54. Szafran et al., “Jackson Pollock's Mural: Myth and Substance,” 49.

55. Szafran et al., "Jackson Pollock's Mural: Myth and Substance," 75.

56. Michael Fried, "Three American Painters" [1965], in idem, Art and Objecthood, 213-65, at 223.

57. Guggenheim complained that her companion, Kenneth Macpherson, "never allowed me to light [Mural], saying the light I had installed especially for it blew out all the fuses," in Peggy Guggenheim, Out of This Century: Confessions of an Art Addict [1946] (New York: Universe Books, 1979), 296. I thank the anonymous reader of this essay for calling this to my attention, as well as for other generous comments.

58. On Pollock's debt to Mexican muralism, see Robert Storr, “A Piece of the Action," in Jackson Pollock: New Approaches, ed. Kirk Varnedoe and Pepe Karmel (New York: Museum of Modern Art, 1999), 33-70. See also Laurance P. Hurlburt, “The Siqueiros Experimental Workshop: New York, 1936,” Art Journal 35 , no. 3 (Spring 1976): 237-46.

59. Ironically, Pollock's placement with the Works Progress Administration's Federal Art Project, which constituted a kind of public support for him as an artist, was terminated in 1943 after eight years. His means to make a painting of mural size soon after was ensured only by the largesse of the wealthy Guggenheim's private patronage. On the consequences of this support for our assessment of Pollock's achievement, see Thomas Crow, "Fashioning the New York School," Modern Art in the Common Culture (New Haven, CT: Yale University Press, 1996), 39-48.

6o. Viewers disagree on this point. Francis V. O'Connor suggests that the direction of movement is left to right in “Jackson Pollock's Mural for Peggy Guggenheim: Its Legend, Documentation, and Redefinition of Wall Painting," in Peggy Guggenheim \& Frederick Kiesler: The Story of Art of This Century, ed. Susan Davidson and Philip Rylands (New York: Guggenheim Museum Publications, 2004), 150-69, at 162. So does Caroline Jones in Eyesight Alone: Clement Greenberg's Modernism and the Bureaucratization of the Senses (Chicago: University of Chicago Press, 2005), 233. David Anfam asserts the opposing view in Jackson Pollock's Mural: Energy Made Visible (New York: Thames \& Hudson, 2015), 22; as do the Getty conservators in Jackson Pollock's Mural: The Transitional Moment, 86. The point is that Pollock made it difficult to decide.

61. For my full account of these issues, see Michael Schreyach, Pollock's Modernism (New Haven, CT: Yale University Press, 2017), 53-96. On Siqueiros’s anamorphosis, see Mari Carmen Ramírez, “The Masses Are the Matrix: Theory and Practice of the Cinematographic Mural in Siqueiros," in Portrait of a Decade, 1930-1940: David Alfaro Siqueiros, ed. Olivier Debroise, exh. cat. (Mexico City: Museo Nacional de Arte, 1997), 68-95; and Jennifer A. Jolly, “Siqueiros' Communist Proposition for Mexican Muralism: A Mural for the Mexican Electricians' Syndicate," in Mexican Muralism: A Critical History, ed. Alejandro Anreus, Leonard Folgarait, and Robin Adèle Greeley (Berkeley: University of California Press, 2012), 75-92.

62. For a number of critical essays regarding the relationship of autonomy to meaning, the reader is directed to peruse the contents of the quarterly journal nonsite.org. 